\title{
Stone removing efficiency and safety comparison between single use ureteroscope and reusable ureteroscope: a systematic review and meta-analysis
}

\author{
Yu-Cheng Ma", Zhong-Yu Jian", Xi Jin, Hong Li, Kun-Jie Wang \\ Department of Urology, Institute of Urology (Laboratory of Reconstructive Urology), West China Hospital, Sichuan University, Chengdu, China \\ Contributions: (I) Conception and design: KJ Wang; (II) Administrative support: KJ Wang, H Li; (III) Provision of study materials or patients: YC \\ Ma, ZY Jian; (IV) Collection and assembly of data: YC Ma, ZY Jian, X Jin; (V) Data analysis and interpretation: YC Ma, ZY Jian; (VI) Manuscript \\ writing: All authors; (VII) Final approval of manuscript: All authors. \\ \#These authors contributed equally to this work and should be considered as co-first authors. \\ Correspondence to: Kun-Jie Wang, MD, PhD. Department of Urology, Institute of Urology (Laboratory of Reconstructive Urology), West China \\ Hospital, Sichuan University, Chengdu 610041, China. Email: wangkj@scu.edu.cn.
}

Background: Urologists are gradually beginning to use single-use ureteroscopes (sufURSs), despite a lack of high-level evidence as to their efficacy and safety. This systematic review was registered on PROSPERO (no. CRD42020181808).

Methods: The PubMed, Embase, Web of Science, and Cochrane Library databases were searched for studies published before October 1, 2020. Jadad score tools were used to evaluate the quality of the included randomized controlled trials (RCTs) and the Newcastle-Ottawa Scale (NOS) was used to evaluate the quality of the included nonrandomized studies. Two researchers independently extracted data according to the Preferred Reporting Items for Systematic Reviews and Meta-Analyses (PRISMA) principles. A data synthesis was performed using Stata 15.0. Heterogeneity was mainly evaluated with I2 tests. In addition to funnel plots, Egger's and Begg's tests were used to detect publication bias. A sensitivity analysis was also performed. Stone-free rates and postoperative complications were the 2 primary outcomes; operation-time data were also extracted.

Results: Six studies (comprising 887 patients) containing the efficacy data and 5 studies (comprising 952 patients) containing the safety data that were finally included in the quantitative analysis. In relation to stone removal, no significant difference was found in terms of efficacy [Mantel-Haenszel statistic (M-H), relative risk (RR): $1.01,95 \%$ confidence interval $(\mathrm{CI}): 0.96-1.07, \mathrm{P}=0.658)$ or safety $(\mathrm{M}-\mathrm{H}, \mathrm{RR}: 1.30,95 \% \mathrm{CI}$ : $0.96-1.75, \mathrm{P}=0.093$ ) between the sufURS and the reusable flexible ureteroscope (rfURS), and no significant heterogeneity was found. A publication bias was detected in the efficacy comparison; however, the trim-andfill analysis indicated that the original synthesis results remained stable.

Conclusions: In relation to stone removal, sufURSs were found to be comparable to rfURS, and no compromising complications were found. However, the results should be treated with caution due to limitations related to the small number of studies included in the analysis.

Keywords: Single-use ureteroscope; reusable ureteroscope; ureteroscopy; meta-analysis

Submitted Nov 07, 2020. Accepted for publication Feb 10, 2021.

doi: 10.21037/tau-20-1399

View this article at: http://dx.doi.org/10.21037/tau-20-1399 


\section{Introduction}

As a minimally invasive surgical intervention, ureteroscopy has been widely used in the diagnosis and treatment of urolithiasis, urothelial tumor, and many other diseases (1). The use of ureteroscopies to treat related diseases has greatly increased; however, urologists and manufacturers of this device have expressed increasing concern about the costrelated issues associated with the use of this device. The flexible ureteroscope is a relatively expensive instrument in urology departments, and many cost-related studies have been published to help users of reusable ureteroscopes reduce costs (2-4). To address issues related to the costs associated with reusable flexible ureteroscopes (rfURSs), many types of single-use flexible ureteroscopes (sufURSs) have been introduced. Some studies have noted that the use of sufURSs in small-capacity medical centers has economic advantages (5-9). However, there is a lack of high-level evidence comparing the safety and efficacy between the sufURS and rfURS. In this study, published data were collected for a meta-analysis to examine the efficacy and safety of the 2 types of scopes. This systematic review was registered on PROSPERO (no. CRD42020181808). We present the following article in accordance with the PRISMA reporting checklist (10) (available at http://dx.doi.org/10.21037/ tau-20-1399).

\section{Methods}

\section{Original study search}

The PubMed, Embase, Web of Science, and Cochrane Library databases were searched to identify relevant studies. The keywords used in the searches included "singleuse ureteroscope," and "disposable ureteroscope." The reference list of every identified publication was manually screened by the authors to identify any studies that had not been captured in the database search procedure.

In accordance with the patient/population, intervention, comparison and outcomes (PICOS) principles, studies had to meet the following inclusion criteria to be included in the meta-analysis: (I) the patients had urinary stones that could be treated with an ureteroscopic lithotripsy or an upper urinary tract disease that could be diagnosed by an ureteroscopy; (II) the only intervention used was that of a ureteroscopic treatment; (III) the studies compared the sufURS and the rfURS; (IV) the results included basic outcome information (e.g., success rates and postoperative complications); and (V) either a randomized control trial
(RCT) or a prospective study design was used. Studies were excluded from the meta-analysis if they met the following exclusion criteria: (I) the study examined previously published reviews; and/or (II) the study undertook a metaanalysis. Letters, comments, and conference abstracts were also excluded from the meta-analysis.

\section{Research quality evaluation}

In relation to the RCTs included in the meta-analysis, quality evaluations were conducted based on Jadad scores. All included nonrandomized studies were evaluated using the Newcastle-Ottawa Scale (NOS). The evaluation procedure was independently performed by 2 authors (YCM and ZYJ); in the event of a disagreement, $\mathrm{KJW}$ re-evaluated the authors' decisions.

\section{Data extraction and synthesis}

This study compared the efficacy and safety of 2 types of ureteroscopes. The main disease examined in the included studies was urinary calculi. Thus, in terms of comparing efficacy, the main comparator was the stone-removal performance of the 2 types of scope. However, in terms of comparing safety, as the studies included did not provide any detailed information about complications, only the overall complication rate could be compared. Data on the number of stone-free patients, the number of patients with postoperative complications, and the total number of patients were extracted from the included studies. The data collection procedures were carried out and double checked independently by 2 authors (YCM and ZYJ). The data synthesis procedures were executed in a Stata 15.0 environment (Stata Corpor, College Station, TX, USA) with the help of RevMan 5.3 software (Cochrane). In the absence of special instructions, the results were defined as statistically significant if $\mathrm{P}<0.05$. The $95 \%$ confidential intervals ( $95 \% \mathrm{CI}$ ) for the main outcomes were also provided. Relative risk (RR) was synthesized as the main estimate. Heterogeneity was mainly evaluated by $\mathrm{I}^{2}$ tests. When $\mathrm{I}^{2}>50 \%$, heterogeneity was considered significant, and a random effects model was applied. To identify any potential factors that might contribute to heterogeneity, a subgroup analysis was performed to gather more information. A sensitivity analysis was used to test the stability of the meta-analysis results. Forest plots were produced to display the main results. In addition to funnel plots, Egger's and Begg's tests were used to detect 


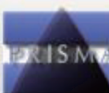

PRISMA 2009 Flow Diagram
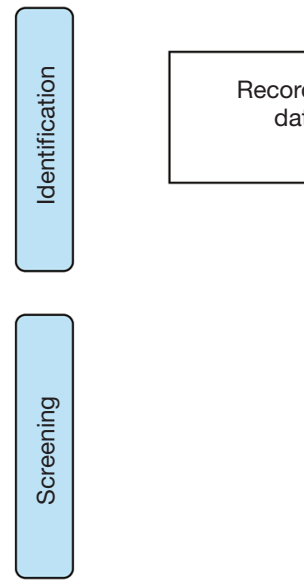

ecords identified through database searching $(n=791)$

Additional records identified through other sources
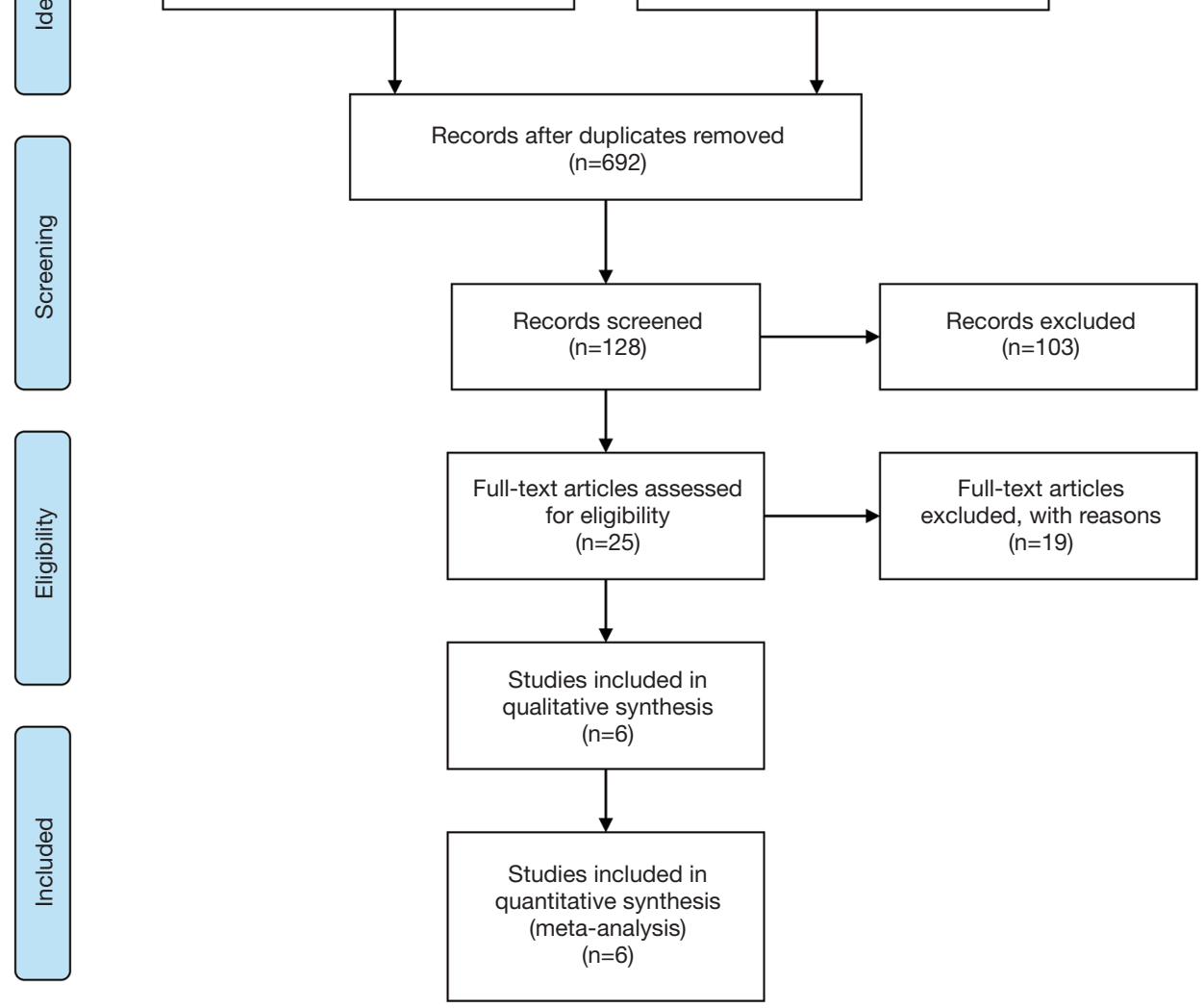

Figure 1 Study selection flowchart.

any publication bias. Any detected publication bias was reanalyzed using the trim-and-fill method to evaluate the effect of the publication bias on the meta-analysis results.

\section{Results}

\section{Study selection}

In total, 791 studies were identified from the database searches. After the screening procedures and quality evaluations had been applied, the original data, which were extracted from 6 studies, were included in the quantitative analysis (5,11-15). Figure 1 shows the screening flow chart. In all, 6 studies (comprising 887 patients) compared the stone-removal efficacy of the sufURS and the rfURS; 5 studies (comprising 952 patients) compared the overall safety of the sufURS and rfURS. Of the 6 studies, 2 studies were RCTs and 4 studies were prospectively designed. Table 1 provides detailed information about the included studies. Tables S1 and S2 display the Jadad and NOS scale results.

\section{Stone-removal efficacy comparison}

Data on the urinary stone treatment from the 6 studies (comprising 887 patients) were included in the efficacy comparison of the sufURS and rfURS. According to the overall synthesis results, no significant difference was found 


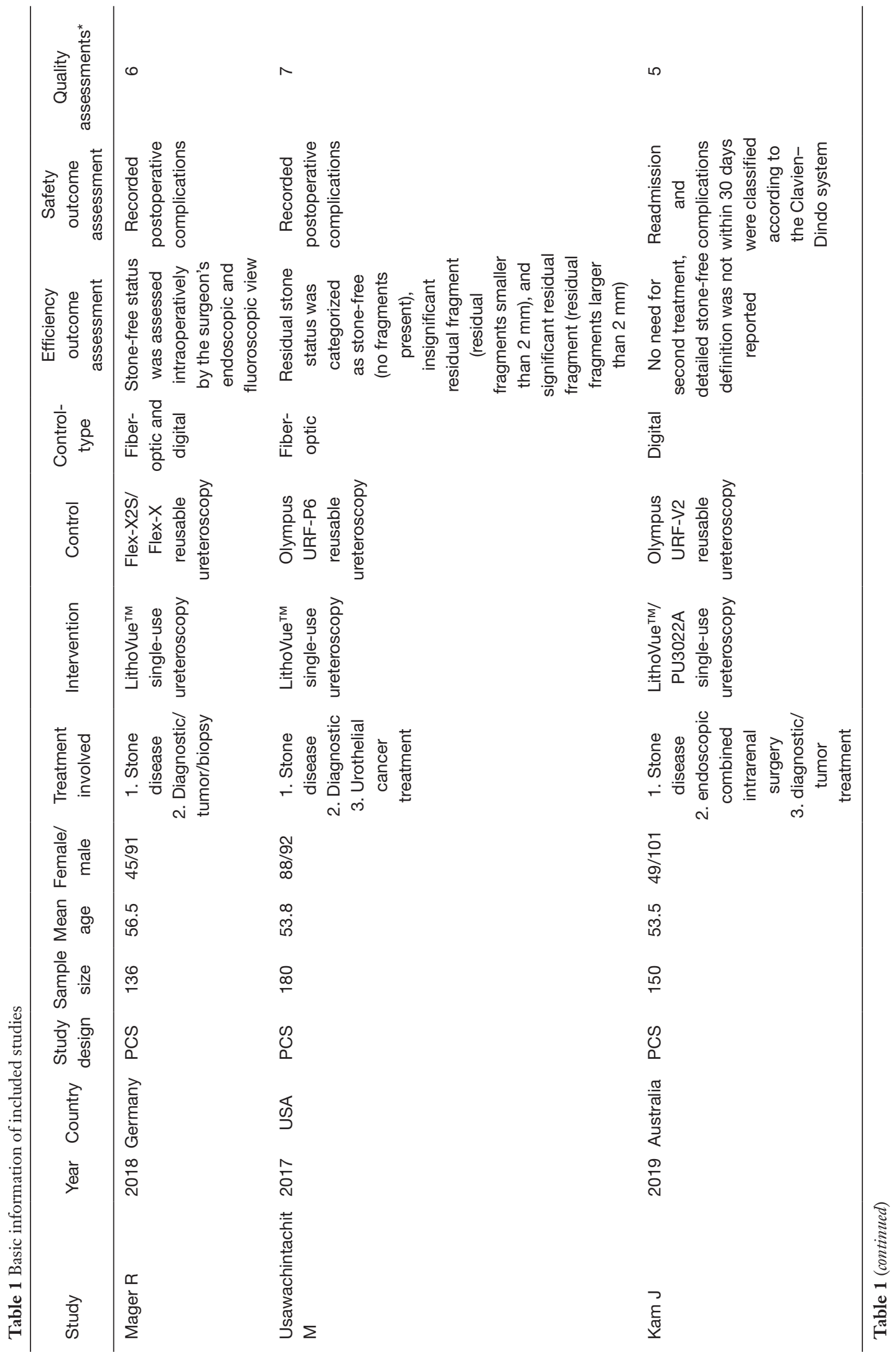




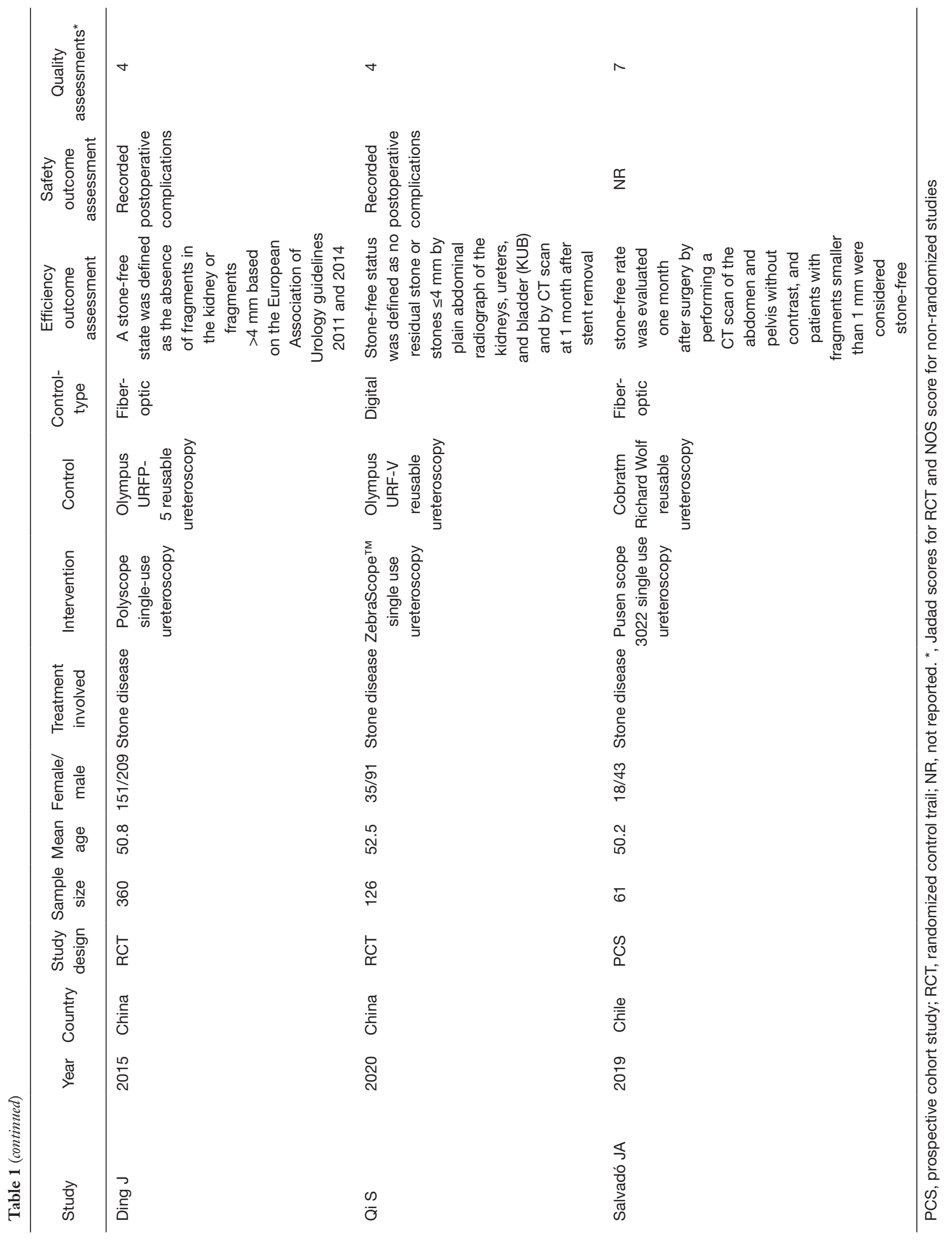



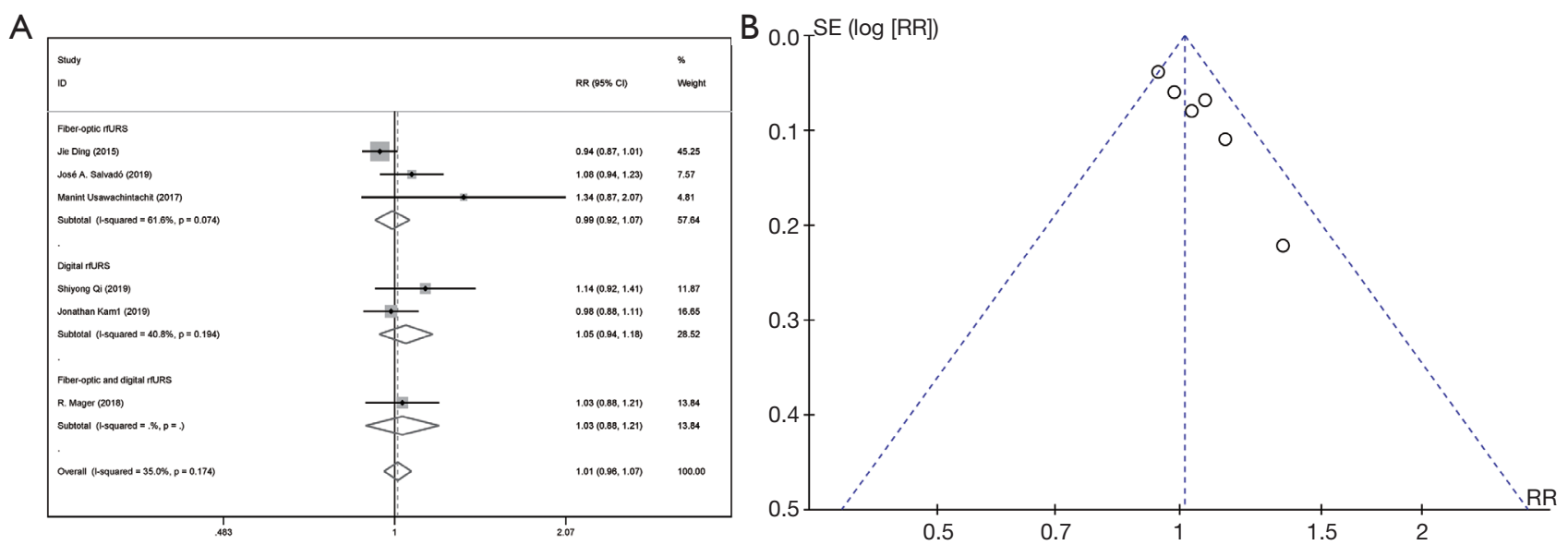

Figure 2 Forest plot of efficiency data synthesis and visualized publication bias analysis based on funnel plots, the overall analysis and subgroup analysis based on different rfURS results indicated that no significant efficiency difference was detected. (A) Forest plot of efficiency comparison between single use flexible ureteroscope and reusable flexible ureteroscope. (B) Funnel plot of efficiency comparison.

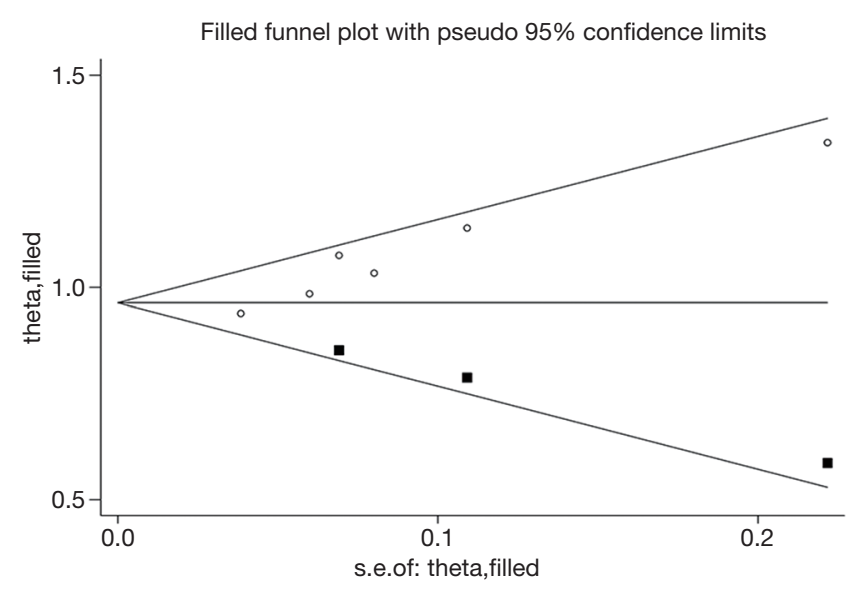

Figure 3 Trim-and-fill funnel plot. Small black cubes mean possible missing studies.

between the stone-removal efficacy of the sufURS and the rfURS [Mantel-Haenszel statistic (M-H), RR: 1.01, 95\% CI: $0.96-1.07, \mathrm{P}=0.658]$, and no significant heterogeneity was found $\left(\mathrm{I}^{2}=35 \%, \mathrm{P}=0.174\right)$. These results were consistent with the subgroup analysis of different rfURS types [sufURS vs. fiber-optic rfURS (M-H, RR: 0.99, 95\% CI: 0.92-1.07, $\mathrm{P}=0.800)$ and sufURS $v$ s. digital rfURS (M-H, RR: 1.05, 95\% CI: 0.94-1.18, $\mathrm{P}=0.410)$ ] (see Figure 2). According to the Egger's $(\mathrm{t}=5.87, \mathrm{P}=0.004)$ and Begg's $(\mathrm{z}=2.25, \mathrm{P}=0.024)$ test results, publication bias was suspected. The funnel plot was asymmetric (see Figure 3). As no significant heterogeneity was found, a further trim-and-fill analysis was conducted. The trim-and-fill results indicated that there might be three possible missing studies; however, both the original results and filled result were consistently nonsignificant (original RR: 1.01, 95\% CI: 0.97-1.16, $\mathrm{P}=0.658$; filled RR: 0.964, 95\% CI: 0.917-1.011, $\mathrm{P}=0.151$ ) (see Figure 4). Thus, the original results were stable. A sensitivity analysis was also performed, and no unstable omission was found (see Table S2). A further subgroup analysis was also conducted, and no significant association was found (see Table 2).

\section{Safety comparison}

Data from 5 studies (comprising 952 patients) were included in the efficacy comparison of the sufURS and the rfURS. In relation to safety, no significant difference between the sufURS and the rfURS (M-H, RR: 1.30, 95\% CI: 0.96-1.75, $\mathrm{P}=0.093)$ was found without significant heterogeneity $\left(\mathrm{I}^{2}=31.3 \%, \mathrm{P}=0.213\right)$. These results were consistent with the subgroup analysis (sufURS $v s$. fiber-optic rfURS: M-H, RR: $1.17,95 \%$ CI: 0.80-1.71, P=0.409; sufURS vs. digital rfURS: M-H, RR: 1.26, 95\% CI: 0.70-2.28, $\mathrm{P}=0.443$ ] (see Figure $2 B$ ). The results of the Egger's ( $\mathrm{t}=0.72$, $\mathrm{P}=0.524)$ and the Begg's tests $(\mathrm{z}=0.24, \mathrm{P}=0.806)$ showed no publication bias. The funnel plot was symmetrical (see Figure 3B). The sensitivity analysis showed that if the study by Usawachintachit [2017] was omitted, the pooled results would indicate that the rfURS was significantly safer than the sufURS (see Table S3). However, no significant 

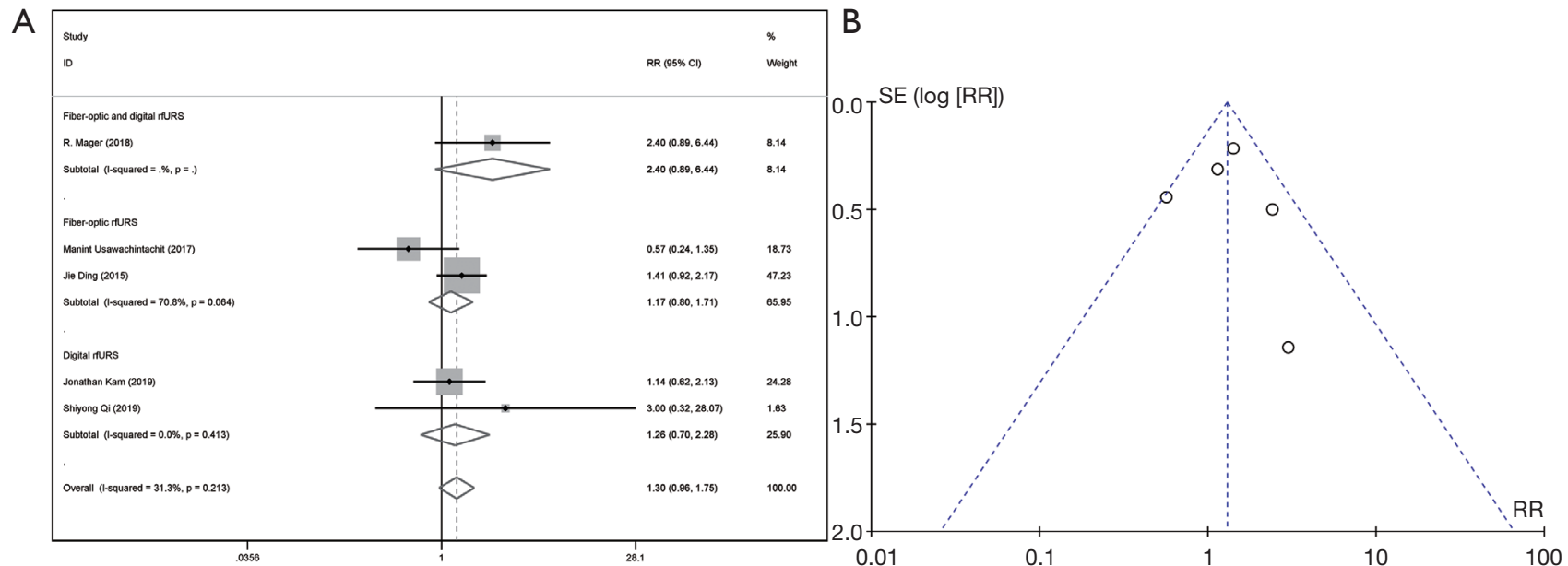

Figure 4 Forest plot of safety data synthesis and visualized publication bias analysis based on funnel plots, the overall analysis and subgroup analysis based on different rfURS results indicated that no significant safety difference was detected. (A) Forest plot of safety comparison between single use flexible ureteroscope and reusable flexible ureteroscope. (B) Funnel plot of safety comparison.

association was found in the potential factor subgroup analysis (see Table 3).

\section{Discussion}

Since the original flexible ureteroscope was invented in the 1960s, a series of technological innovations have led to the introduction many flexible ureteroscope types, such as the fibric scope and digital scope (1). Due to the expansion of its applications, the maintenance costs and other issues associated with rfURSs have gradually increased (16), and the sufURS was developed to address the issues related to maintenance.

This meta-analysis showed that there was no significant difference in the efficacy and safety of the sufURS and the rfURS. In the efficacy comparison, the Begg's and Egger's tests results showed a significant publication bias. In the subsequent trim-and-fill analysis, the results showed that 3 studies appeared to be missing. After the missing data was filled, the trim-and-fill results still showed that there were no significant differences between the sufURS and the rfURS (original RR: 1.01, 95\% CI: 0.97-1.16; filled RR: 0.964, 95\% CI: $0.917-1.011)(17)$. In relation to the safety comparison, the results of the sensitivity test were unstable. Thus, more clinical trials need to be conducted so that a more stable safety evaluation can be made.

In addition to the various direct and indirect costs associated with rfURS use that are incurred in the processes of sterilization, storage, and reprocessing, the high repairs cost that arise if a rfURS is damaged significantly increase its total maintenance costs (18). In some reports, the overall maintenance cost has been reported to be $€ 384$ per treatment case (9). Such costs might be unacceptable for small capacity institutions. According to previous research, the use of a sufURS may represent a good solution for small-scale medical institutions with less than 61 flexible ureteroscope cases per year, especially for those without a plasma standardization system (5). Additionally, in terms of cost-effectiveness, some published studies have noted that disposable ureteroscopes are more cost-effective than reusable ureteroscopes after a small number of procedures (7).

However, as a consumable, the primary material of the sufURS is plastic and many elaborate designs have been simplified. These design changes have reduced the weight of the main body, but they have also reduced its operability. This study also compared operation times and found that the operation time of the sufURS was significantly more than that of the rfURS [weighted mean difference (WMD): 7.943, 95\% CI: 5.108-10.779, $\mathrm{P}<0.001$ ] (see Figure $\mathrm{S} 1$ ). The comparison of the operation times was relatively heterogeneous; however, the results still suggest that the operability of sufURSs could be improved. In addition to increasing operation time, the reduced operability of sufURSs may also increase total complication rates and decrease overall efficacy. Given that the sufURS does not require repeated disinfection, we expected that it would have a higher level of performance in terms of the control of postoperative infections. 
Table 2 Subgroup analysis of efficiency data-synthesis

\begin{tabular}{|c|c|c|c|c|c|}
\hline Category of variables & \multicolumn{4}{|c|}{ Heterogeneity } & $P$ value for difference \\
\hline Efficiency & 6 & & & & \\
\hline \multicolumn{6}{|l|}{ Study design } \\
\hline Randomized & 2 & 68.4 & 0.075 & $0.98(0.91,1.06)$ & 0.613 \\
\hline \multicolumn{6}{|l|}{ Geographic area } \\
\hline Asia & 2 & 68.4 & 0.075 & $0.98(0.91,1.06)$ & 0.613 \\
\hline America & 2 & 52.4 & 0.147 & $1.18(0.97,1.43)$ & 0.102 \\
\hline Europe & 1 & - & - & $1.03(0.88,1.21)$ & 0.682 \\
\hline LithoVue & 3 & 19.2 & 0.290 & $1.05(0.95,1.17)$ & 0.342 \\
\hline Polyscope & 1 & - & - & $0.94(0.87,1.01)$ & 0.102 \\
\hline ZebraScope & 1 & - & - & $1.14(0.92,1.41)$ & 0.232 \\
\hline Pusen & 1 & - & - & $1.08(0.94,1.23)$ & 0.294 \\
\hline \multicolumn{6}{|l|}{ Stone-free definition } \\
\hline$<2 \mathrm{~mm}$ & 1 & - & - & $1.34(0.87,2.07)$ & 0.186 \\
\hline$<4 \mathrm{~mm}$ & 2 & 68.4 & 0.075 & $0.98(0.91,1.06)$ & 0.613 \\
\hline Other definition & 3 & 0.0 & 0.622 & $1.02(0.94,1.11)$ & 0.626 \\
\hline
\end{tabular}

$\mathrm{Cl}$, confidence interval; $\mathrm{RR}$, relative risk.

However, according to the results of the safety data synthesis, there was no significant difference between the sufURS and the rfURS (M-H, RR: 1.30, 95\% CI: 0.96$1.75, \mathrm{P}=0.093)$. This may be because most hospitals that carry out clinical research adequately disinfect the rfURS. Many factors can affect the occurrence of postoperative infections; however, due to its nonreusable characteristics, the sufURS can predictably avoid contamination in the area of instrument disinfection. The sufURS appears to be comparable to the rfURS; however, the sufURS has many advantages. A proper disinfection and sterilization process has been developed, but the reuse of medical equipment can still lead to cross contamination. Additionally, being cleaned and disinfected too many times can also affect the service life of extremely vulnerable equipment, such as the rfURS. The use of disposable equipment completely eradicates this problem.

This study had a number of limitations. First, different reusable ureteroscopes were considered in this study, and while the subgroup analyses examined different reusable ureteroscope types, each subgroup's study number was small. Second, only 2 RCTs were included in the metaanalysis, which could have led to the introduction of bias. Third, while 3 kinds of sufURSs were included in the quantitative analysis, these were all digital and were produced by different manufacturers, which also might have produced bias. Fourth, because of the included studies' limited data, this meta-analysis only compared stone-removal efficacy. Thus, the efficacy of the sufURS in the treatment of other diseases, such as tumors, requires 
Table 3 Subgroup analysis of safety data-synthesis

\begin{tabular}{|c|c|c|c|c|c|}
\hline Category of variables & \multicolumn{4}{|c|}{ Heterogeneity } & $P$ value for difference \\
\hline Safety & 5 & & & & \\
\hline \multicolumn{6}{|l|}{ Study design } \\
\hline Randomized & 2 & 0 & 0.516 & $1.47(0.96,2.23)$ & 0.074 \\
\hline \multicolumn{6}{|l|}{ Geographic area } \\
\hline Asia & 2 & 0 & 0.516 & $1.47(0.96,2.23)$ & 0.074 \\
\hline America & 1 & I & l & $0.57(0.24,1.35)$ & 0.200 \\
\hline Europe & 1 & / & / & $2.40(0.89,6.44)$ & 0.082 \\
\hline LithoVue & 3 & 57.1 & 0.097 & $1.13(0.73,1.75)$ & 0.576 \\
\hline Polyscope & 1 & / & / & $1.41(0.92,2.17)$ & 0.113 \\
\hline ZebraScope & 1 & I & l & $3.00(0.32,28.1)$ & 0.336 \\
\hline \multicolumn{6}{|l|}{ Stone-free definition } \\
\hline$<2 \mathrm{~mm}$ & 1 & / & / & $0.57(0.24,1.35)$ & 0.200 \\
\hline$<4 \mathrm{~mm}$ & 2 & 0 & 0.516 & $1.47(0.96,2.23)$ & 0.074 \\
\hline Other definition & 2 & 36.1 & 0.211 & $1.46(0.87,6.44)$ & 0.153 \\
\hline \multicolumn{6}{|l|}{ Publication year } \\
\hline
\end{tabular}

$\mathrm{Cl}$, confidence interval; RR, relative risk.

further investigation. Finally, only 6 studies were included in this meta-analysis. RCTs with larger sample sizes need to be conducted to enable more sound conclusions to be drawn.

\section{Conclusions}

The meta-analysis of the current evidence showed that the sufURSs and the rfURS are comparable in terms stone removal. Further, no compromising complications were found. The sufURS could represent a good choice for medical centers that have little ureteroscope maintenance experience and relatively few ureteroscope cases. However, the results of this study should be treated with some caution due to the limitations mentioned above.

\section{Acknowledgments}

Funding: Project of Science and Technology Department of Sichuan Province (2018SZ0118), 1.3.5 project for disciplines of excellence, West China Hospital, Sichuan University (ZY2016104, ZYJC18015, and ZYGD18011), Project of Sichuan Provincial Health Department, Dualsource CT dual-energy urography and urolithiasis analysis in the early prevention and treatment of urolithiasis (ChuanGanYanZH2017-101).

\section{Footnote}

Reporting Checklist: The authors have completed the PRISMA reporting checklist. Available at http://dx.doi. org/10.21037/tau-20-1399 
Conflicts of Interest: All authors have completed the ICMJE uniform disclosure form (available at http://dx.doi. org/10.21037/tau-20-1399). The authors have no conflicts of interest to declare.

Ethical Statement: The authors are accountable for all aspects of the work in ensuring that questions related to the accuracy or integrity of any part of the work are appropriately investigated and resolved.

Open Access Statement: This is an Open Access article distributed in accordance with the Creative Commons Attribution-NonCommercial-NoDerivs 4.0 International License (CC BY-NC-ND 4.0), which permits the noncommercial replication and distribution of the article with the strict proviso that no changes or edits are made and the original work is properly cited (including links to both the formal publication through the relevant DOI and the license). See: https://creativecommons.org/licenses/by-nc-nd/4.0/.

\section{References}

1. Reis Santos JM. Ureteroscopy from the recent past to the near future. Urolithiasis 2018;46:31-7.

2. Alsyouf M, Hur D, Stokes P, et al. The Impact of Patient, Procedural, and Staffing Factors Upon Ureteroscopy Cost. J Endourol 2020;34:746-51.

3. Temiz MZ, Colakerol A, Ertas K, et al. Fiberoptic versus Digital: A Comparison of Durability and Cost Effectiveness of the Two Flexible Ureteroscopes. Urol Int 2019;102:181-6.

4. Liu H, Pan W, Zhang N. Ureteral stent removal using an extraction string after uncomplicated ureteroscopy: a costbenefit analysis. Urol J 2018;15:329-32.

5. Mager R, Kurosch M, Hofner T, et al. Clinical outcomes and costs of reusable and single-use flexible ureterorenoscopes: a prospective cohort study. Urolithiasis 2018;46:587-93.

6. Hennessey DB, Fojecki GL, Papa NP, et al. Single-use disposable digital flexible ureteroscopes: an ex vivo assessment and cost analysis. BJU Int 2018;121 Suppl 3:55-61.

7. Al-Balushi K, Martin N, Loubon H, et al. Comparative medico-economic study of reusable vs. single-use flexible ureteroscopes. Int Urol Nephrol 2019;51:1735-41.

8. Davis NF, Quinlan MR, Browne C, et al. Single-use flexible ureteropyeloscopy: a systematic review. World J Urol 2018;36:529-36.

9. Ozimek T, Schneider MH, Hupe MC, et al. Retrospective
Cost Analysis of a Single-Center Reusable Flexible Ureterorenoscopy Program: A Comparative Cost Simulation of Disposable fURS as an Alternative. J Endourol 2017;31:1226-30.

10. Shamseer L, Moher D, Clarke M, et al. Preferred reporting items for systematic review and meta-analysis protocols (PRISMA-P) 2015: elaboration and explanation. Bmj 2015;350:g7647.

11. Usawachintachit $M$, Isaacson DS, Taguchi K, et al. A Prospective Case-Control Study Comparing LithoVue, a Single-Use, Flexible Disposable Ureteroscope, with Flexible, Reusable Fiber-Optic Ureteroscopes. J Endourol 2017;31:468-75.

12. Kam J, Yuminaga $Y$, Beattie K, et al. Single use versus reusable digital flexible ureteroscopes: A prospective comparative study. Int J Urol 2019;26:999-1005.

13. Ding J, Xu D, Cao Q, et al. Comparing the Efficacy of a Multimodular Flexible Ureteroscope With Its Conventional Counterpart in the Management of Renal Stones. Urology 2015;86:224-9.

14. Qi S, Yang E, Bao J, et al. Single-Use Versus Reusable Digital Flexible Ureteroscopes for the Treatment of Renal Calculi: A Prospective Multicenter Randomized Controlled Trial. J Endourol 2020;34:18-24.

15. Salvado JA, Cabello JM, Moreno S, et al. Endoscopic treatment of lower pole stones: is a disposable ureteroscope preferable? Results of a prospective case-control study. Cent European J Urol 2019;72:280-4.

16. Martin CJ, McAdams SB, Abdul-Muhsin H, et al. The Economic Implications of a Reusable Flexible Digital Ureteroscope: A Cost-Benefit Analysis. J Urol 2017;197:730-5.

17. Duval S, Tweedie R. Trim and fill: A simple funnel-plotbased method of testing and adjusting for publication bias in meta-analysis. Biometrics 2000;56:455-63.

18. Marchini GS, Torricelli FC, Batagello CA, et al. A comprehensive literature-based equation to compare cost-effectiveness of a flexible ureteroscopy program with single-use versus reusable devices. Int Braz J Urol 2019;45:658-70.

Cite this article as: Ma YC, Jian ZY, Jin X, Li H, Wang KJ. Stone removing efficiency and safety comparison between single use ureteroscope and reusable ureteroscope: a systematic review and meta-analysis. Transl Androl Urol 2021;10(4):16271636. doi: $10.21037 /$ tau-20-1399 
Supplementary

Table S1 Newcastle-Ottawa scale score of the reviewed non-randomized studies

\begin{tabular}{|c|c|c|c|c|c|c|c|c|c|}
\hline \multirow[b]{2}{*}{ Study } & \multicolumn{4}{|c|}{$\begin{array}{l}\text { Selection } \\
\text { (4 stars) }\end{array}$} & \multirow{2}{*}{$\begin{array}{c}\text { Comparability } \\
(2 \text { stars })\end{array}$} & \multicolumn{3}{|c|}{$\begin{array}{l}\text { Outcome } \\
\text { (3 stars) }\end{array}$} & \multirow[b]{2}{*}{$\begin{array}{l}\text { Total } \\
\text { score }\end{array}$} \\
\hline & $\begin{array}{l}\text { Representativeness } \\
\text { score of the efficiency } \\
\text { and safety of single } \\
\text { use ureteroscopy }\end{array}$ & $\begin{array}{l}\text { Selection of the } \\
\text { efficiency and } \\
\text { safety of single } \\
\text { use ureteroscopy }\end{array}$ & $\begin{array}{l}\text { Ascertainment } \\
\text { of efficiency and } \\
\text { safety of single } \\
\text { use ureteroscopy }\end{array}$ & $\begin{array}{c}\text { Demonstration that } \\
\text { outcome of interest } \\
\text { was not present at } \\
\text { start of study }\end{array}$ & & $\begin{array}{l}\text { Assessment of } \\
\text { outcome }\end{array}$ & $\begin{array}{l}\text { Was follow up } \\
\text { f long enough for } \\
\text { outcomes to } \\
\text { occur? }\end{array}$ & $\begin{array}{l}\text { Adequacy of } \\
\text { follow up of } \\
\text { cohort }\end{array}$ & \\
\hline $\begin{array}{l}\text { R. Mager } \\
2018\end{array}$ & $\star$ & $\star$ & $\star$ & $\star$ & $\star$ & $\star$ & - & - & 6 \\
\hline $\begin{array}{l}\text { Manint } \\
\text { Usawachintachit } \\
2017\end{array}$ & $\star$ & $\star$ & $\star$ & $\star$ & $\star$ & $\star$ & - & $\star$ & 7 \\
\hline $\begin{array}{l}\text { Jonathan Kam } \\
2019\end{array}$ & $\star$ & $\star$ & $\star$ & $\star$ & $\star$ & - & - & - & 5 \\
\hline $\begin{array}{l}\text { José A. Salvadó } \\
2019\end{array}$ & $\star$ & $\star$ & $\star$ & $\star$ & $\star$ & $\star$ & - & $\star$ & 7 \\
\hline
\end{tabular}

Table S2 Jadad score of the reviewed RCT.

\begin{tabular}{|c|c|c|c|c|c|}
\hline Study & Design & Randomization & Double blinding & Follow-up & Total points/rank \\
\hline Jie Ding & RCT & 2 & 1 & 1 & 4/High \\
\hline Shiyong Qi & $\mathrm{RCT}$ & 2 & 1 & 1 & 4/High \\
\hline
\end{tabular}

Table S3 Sensitivity analysis of efficiency meta-analysis. CI: Confidence interval.

\begin{tabular}{|c|c|c|c|}
\hline Study omitted & Estimate & \multicolumn{2}{|c|}{$95 \% \mathrm{Cl}$} \\
\hline Jie Ding (2015) & 1.07 & 0.99 & 1.17 \\
\hline Shiyong Qi (2019) & 0.99 & 0.94 & 1.06 \\
\hline José A. Salvadó (2019) & 1.01 & 0.95 & 1.07 \\
\hline R. Mager (2018) & 1.01 & 0.95 & 1.07 \\
\hline Manint Usawachintachit (2017) & 0.99 & 0.94 & 1.05 \\
\hline Jonathan Kam (2019) & 1.02 & 0.95 & 1.09 \\
\hline
\end{tabular}

Table S4 Sensitivity analysis of safety meta-analysis. CI: Confidence interval.

\begin{tabular}{|c|c|c|c|}
\hline Study omitted & Estimate & \multicolumn{2}{|c|}{$95 \% \mathrm{Cl}$} \\
\hline R. Mager (2018) & 1.20 & 0.87 & 1.65 \\
\hline Manint Usawachintachit (2017) & 1.46 & 1.06 & 2.03 \\
\hline Jonathan Kam (2019) & 1.34 & 0.95 & 1.90 \\
\hline Jie Ding (2015) & 1.19 & 0.78 & 1.82 \\
\hline Shiyong Qi (2019) & 1.27 & 0.93 & 1.72 \\
\hline
\end{tabular}




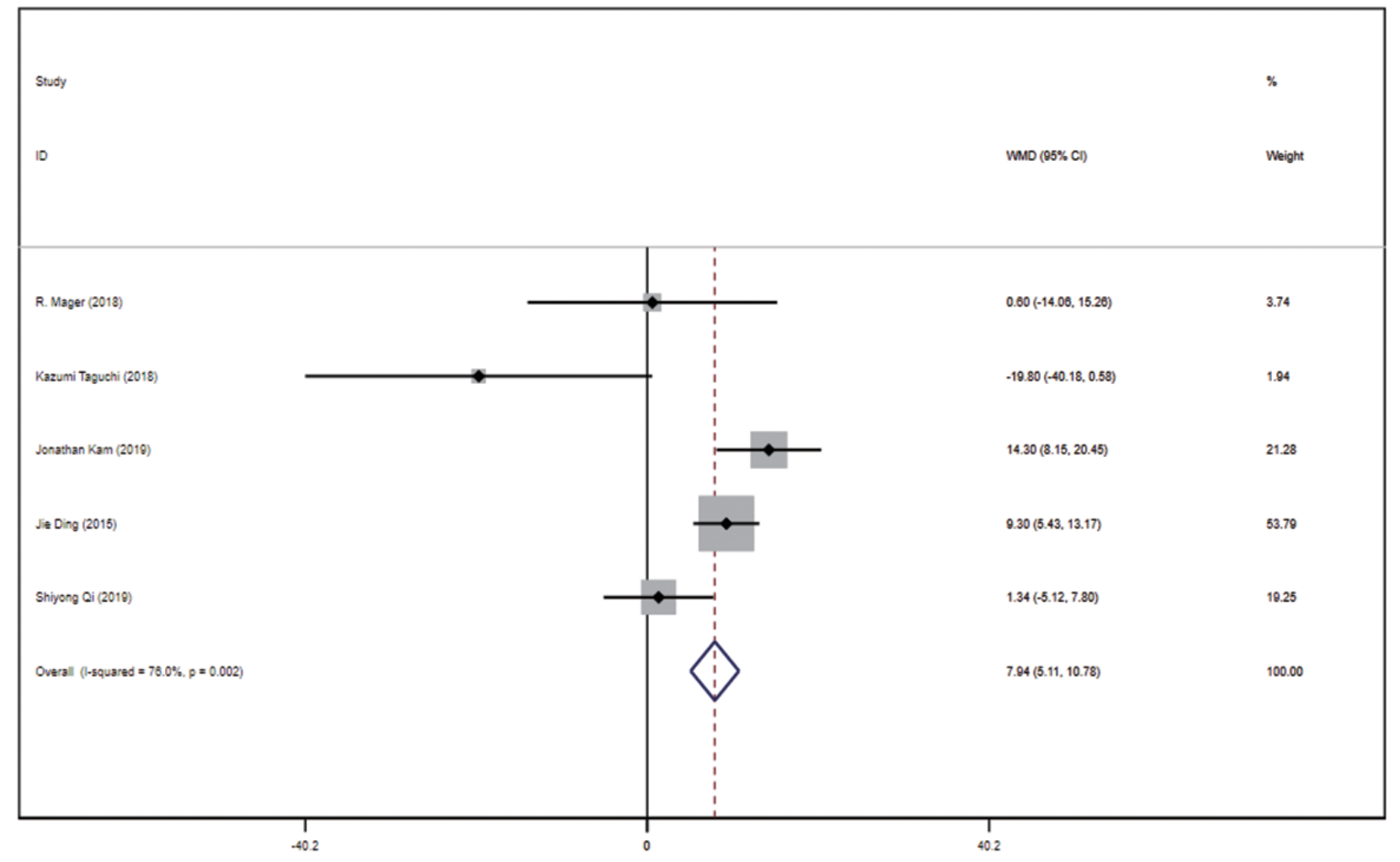

Figure S1 Funnel plot of operation time comparison between single-use ureteroscope and reusable ureteroscope. 